Int. J. Dev. Biol. 54: 1019-1031 (2010)

doi: $10.1387 / \mathrm{ijdb} .093039$ hu

\title{
The origin and fate of yolk sac hematopoiesis: application of chimera analyses to developmental studies
}

\author{
HIROO UENO* and IRVING L. WEISSMAN \\ Institute of Stem Cell Biology and Regenerative Medicine, Departments of Pathology and Developmental \\ Biology, Ludwig Institute at Stanford University, Stanford University, Stanford, CA, USA
}

\begin{abstract}
During mammalian development, as exemplified by mice, hematopoietic cells first appear in the yolk sac blood islands, then in the dorsal aorta of the aorta-gonad-mesonephros (AGM) region and the placenta, eventually seeding into liver, spleen and then bone marrow. The formation of hematopoietic stem cells from mesodermal precursors has finished by mid-fetal life. Once established, the hematopoietic system must supply blood cells to host circulation and tissues for the entire life of the animal. Easy access to hematopoietic cells has enabled a vast number of studies over the last several decades, and much is now understood about the different hematopoietic lineages, how they differentiate, and their derivation from immature progenitors. Yet to be elucidated are the following two intriguing questions: do yolk sac and AGM hematopoietic cells arise from a common precursor or from distinct precursor cells?; and what is the lineage relationship between blood and endothelial cells. In this review, we will survey the state of our current knowledge in these areas, and discuss the potential use of multicolor chimera analyses to elucidate unresolved questions.
\end{abstract}

KEY WORDS: chimeras, mosaic, development, stem cells, lineage tracing

\section{Mosaic analyses}

\section{Advantages and limitations of clonal analysis by chimeras}

The formation of chimeric mice which have deleted a specific gene or introduced a novel one is a common practice today, readily achieved by blastocyst injection of embryonic stem (ES) cells or aggregation of early embryos with ES cells. However, these methods were originally developed for studies of mouse embryogenesis, and used extensively in lineage tracing experiments. In the 1960's Tarkowski found that two 8-cell stage embryos deprived of zona pellucida can fuse together and develop into a chimeric blastocyst in vitro. The resulting chimeric embryos transplanted back to the uterus of pseudo-pregnant foster mothers develop normally and gave rise to chimeric mice (Tarkowski, 1961). If two embryos used to create chimeras are derived from strains with distinguishable markers, it is possible to follow the fate of cells originating from each embryo. Later, it was found that dissociated inner cell mass cells from blastocyst stage embryos can form chimeras by injecting them into the blastocoele of another blastocyst stage embryo (Gardner, 1968; Gardner, 1978). In 1981, Evans and Martin developed a method to culture inner cell mass cells in vitro and established mouse embryonic stem (ES) cells (Evans and Kaufman, 1981; Martin, 1981), a discovery which subsequently enabled the generation of chimeric mice by blastocyst injection.

Another strategy for creating chimeras is to utilize genomic imprinting of X chromosomes in females (Tam and Tan, 1992; Tan and Breen, 1993). In these cases, marker genes, such as lacZ, are integrated into an $\mathrm{X}$ chromosome locus that is susceptible to genomic imprinting. Female mice heterozygous for the marker gene undergo genomic imprinting, which results in a situation where half of the somatic cells lose the marker expression, while the other half retain the marker during development and throughout life. This strategy is more convenient than the methods described above using blastocyst injection/embryo fusion. In each case, chimeras are composed of two cell types, most typically lacZ positive and negative cells. Clearly such experiments cannot be performed in humans, however, naturally occur-

Abbreviations used in this paper: AGM, aorta-gonad-mesonephros; CFU, colony forming unit; CMP, common myeloid progenitors; ES, embryonic stem cells; HSCs, hematopoietic stem cells; ICM, inner cell mass; P-Sp, paraaortic splanchnopleura.

\footnotetext{
*Address correspondence to: Hiroo Ueno. 279 Campus Drive, B259 Beckman Center, Stanford, CA 94305-5323, USA. Fax: +1-650-723-4034. e-mail: hueno@stanford.edu
} 


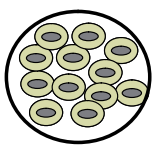

If the tissue originates from one cell
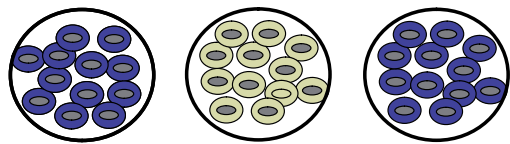

If the tissue originates from two cells
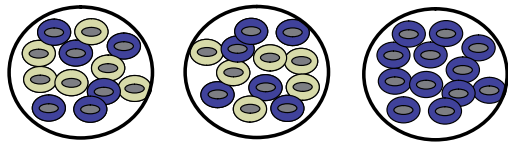

Fig. 1. Clonal analyses of tissues using marker-positive and negative mouse chimeras.

ring human chimeras (such as $\mathrm{XY} / \mathrm{XO}$ individuals) do exist at low frequency and could theoretically be used for the lineage tracing of cancer development (Novelli et al., 1996).

Another simple and classical way to increase complexity of mosaicism is making use of retrovirus integration into the genome. Because integration sites of retroviruses are random, every cell could be labeled distinctly by this method. For example, assuming that all the cells are labeled at a specific point of mouse development, progeny of a single cell would all have proviruses in the same integration sites. In one elegant application of this method, Soriano et al. reported that somatic lineages are derived from at most eight founder cells (Soriano and Jaenisch, 1986). Unfortunately the labeled cells could not be visualized or distinguished in situ, thereby limiting the application of this methodology to lineage tracing of major populations. In recent years, creloxp mediated genetic mosaic mice have been developed (Zong et al., 2005; Livet et al., 2007). This system is particularly attrac-
A
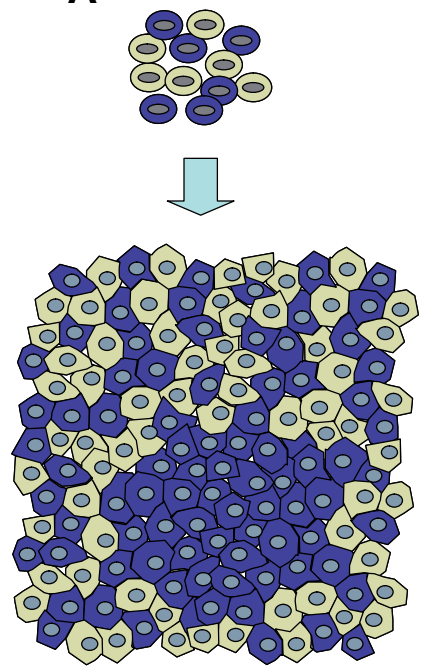

B

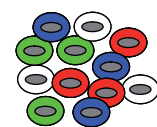

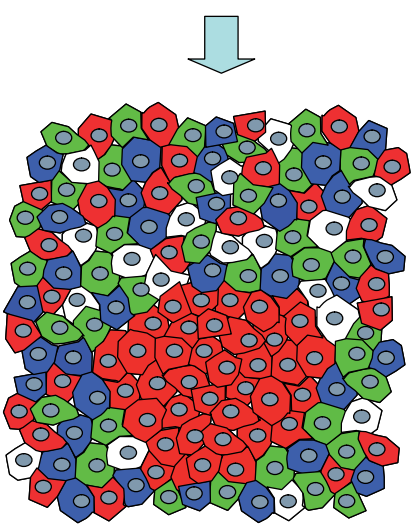

tive, since selection of appropriate markers can yield animals where the gene is expressed in a tissue-specific and/or inducible manner.

\section{Advantages of using multiple markers for chimeric analysis}

Conventional single marker chimeras have been used to examine whether the origin of one particular tissue of interest is monoclonal or polyclonal. In one typical example, a single marker chimerism was used as evidence that within adult intestinal epithelial cells, each crypt develops from a single cell progenitor (Ponder etal., 1985). The method was also utilized to estimate the number of progenitors that generate a particular tissue. However most attempts to utilize single marker chimeras and statistical analyses have been unsuccessful (reviewed by McLaren et al., (Lewis et al., 1972; McLaren, 1972; West, 1975)). One reason for this is that the complexity of chimerism created by single markers (i.e. two color chimeras composed of marker positive and negative cells) is limited. In light of the previous discussion, one idea for widening the applicability of chimeras is to increase the number of markers used to mark cells. If a particular tissue exhibits both marker positive and negative cells, it shows that more than one type of progenitor has given rise to the tissue. It is more difficult to interpret a single tissue exhibiting a single color, because this can be explained by the tissue being entirely derived from a single precursor, or from multiple precursors that happen to express the same color-encoding gene (Fig. 1). In single-color chimeras, a tissue derived from a single cell generally forms a cell cluster expressing a single color. However, if the area is small and the boundary between the area and the color-lacking surrounding cells is unclear, precise interpretation may be difficult (Fig. 2A). In

A
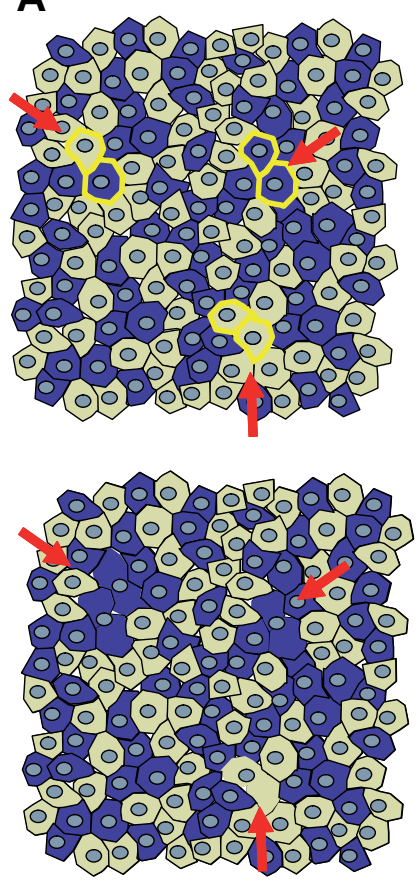

B
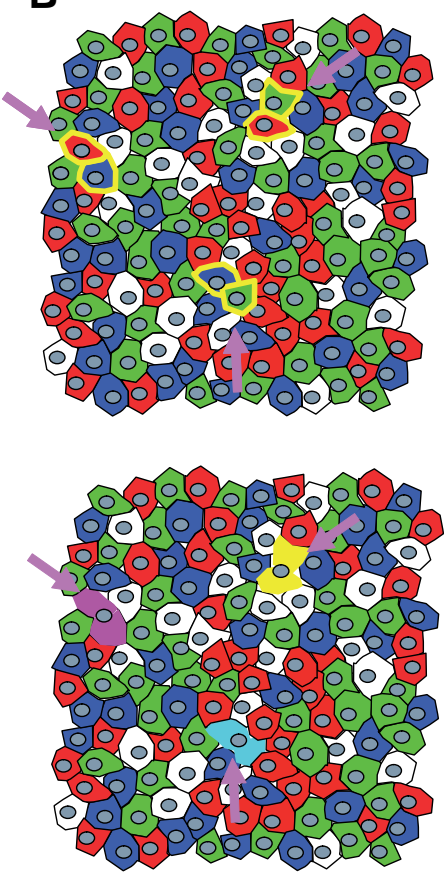

Fig. 2 (Left). Single cell derived areas are easier to detect in multicolor chimeras (B) than in conventional single marker chimeras (A).

Fig. 3 (Right). Cell fusion is easily detected in multicolor chimeras (B), but difficult to detect using conventional marker-positive and negative chimeras (A). 

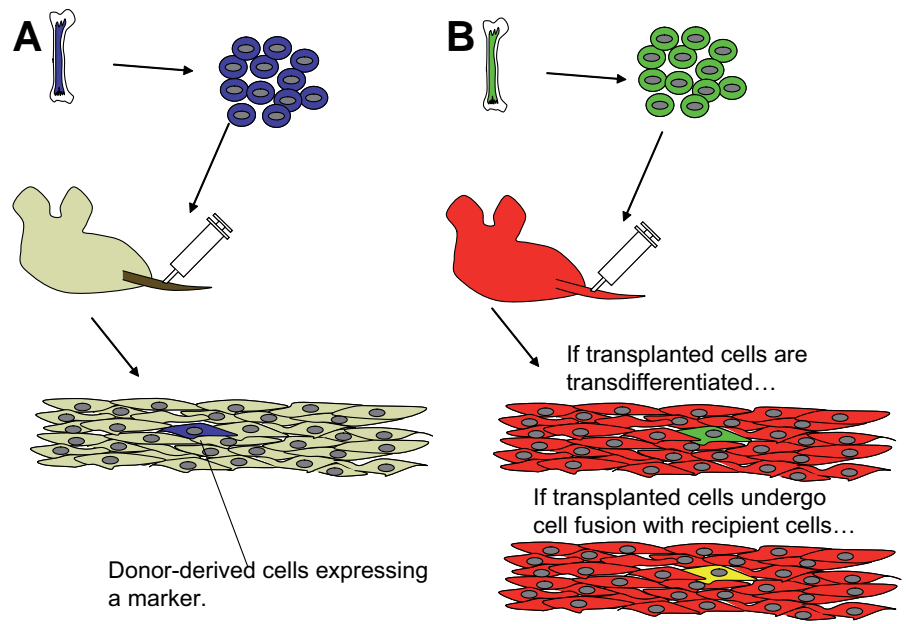

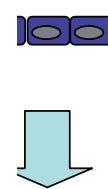

A

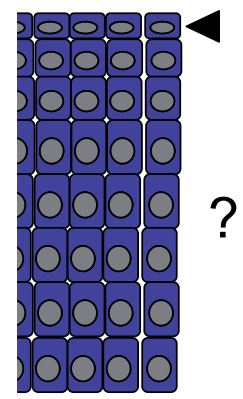

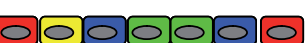

B<smiles>C1CCCC1</smiles>

Stem cells

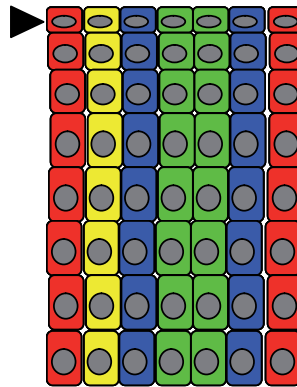

Fig. 4 (Left). Transplantation chimeras. (A) In conventional system, donors are marker positive and recipients are marker negative, by which it is impossible to distinguish transdifferentiated cells and fused cells. (B) If donor and recipient mice have distinct markers, transdifferentiated cells and fused cells could be distinguished by their marker expression.

Fig. 5 (Right). Merit of multicolor reporter system. (A) Conventional reporter mice. (B) Multicolor reporter mice, enabling the tracing of the direction of tissue proliferation or migration.

multiple color chimeras, the border between such single cell derived region and surrounding cells is clearer, improving detection and resolution. (Fig. 2B). Multicolor chimeras also enable detection of cell fusion in situ. The fusion of two cells is an event that occurs in at least some developing tissues. Using single marker chimeras, only three cell fusion phenotypes can be produced: marker-positive/positive, positive/negative and negative/negative. Fused cells in these animals would be marker positive or negative, phenotypes which would be basically indistinguishable from surrounding cells that are unfused (Fig. 3A). In contrast, fused cells in multicolor chimeras will coexpress two different markers if they are derived from two different color expressing cells. Of course, it is not possible in these chimeras to detect fusion of cells expressing the same color, but as the input number of different colored cells increases, the possible frequency of undetected fusions goes down (Fig. 3B). Another advantage of utilizing more than one marker to trace cell relationships and lineages is seen in transplantation models, when cells from a marker-positive mouse are transplanted into a marker negative mouse (transplantation generated chimeras). For example, after bone marrow transplantation, many studies have demonstrated that bone marrow-derived cells or even purified hematopoietic stem cells (HSCs) can contribute to other lineages of cells based on findings that the marker positive cells that are negative for hematopoietic markers such as CD45, appear in

Fig. 6. Failure of contribution of some colors observed in organs derived from oligoclonal progenitors. (A) In multicolor chimeras, tissues or organs that are derived from a small number of progenitors can fail to include all the color clones. (B) Probabilities of "fewer" color tissues in 2-4 color chimeras. $X$-axis, number of progenitors; $Y$ axis probabilities of fewer color organs/tissues (Ueno in preparation).

tissues outside bone marrow (Krause et al., 2001). In most of these cases, careful follow-up studies have revealed that the marker-positive cells are generated by cell fusion (Wagers and Weissman, 2004), which is indistinguishable in color and obviously misleading (Fig. 4A). However, by using different marker mice for donors and recipients, such misinterpretation of results can be avoided (Fig. 4B). In case transplanted cells "transdifferentiate" to other lineages of cells, the donor marker positive cells should be observed in the tissue of interest. However, if transplanted cells undergo cell fusion with recipient cells, donor and recipient marker coexpressing cells should be observed (Fig. 4B).

Another common method for creating chimeras is provided by

A
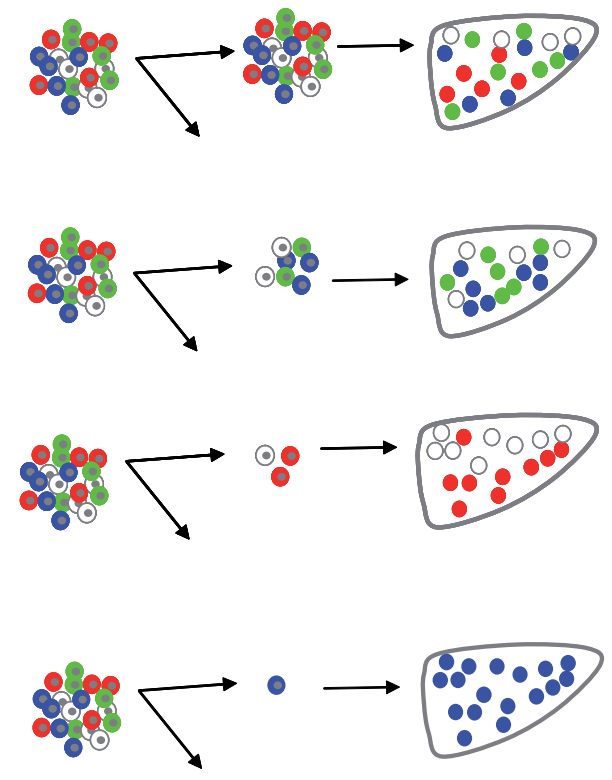

B

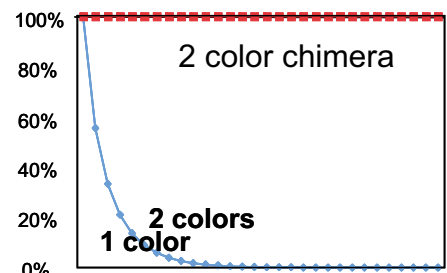

3 color chimera
$20 \%$
$30 \%$
3 colors
$10 \%$

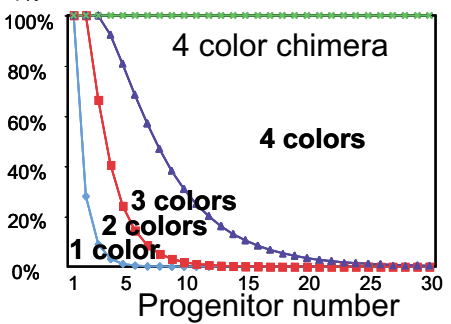


the cre-loxp system, in which cre or cre-ERT2 (Imai et al., 2001; Li etal., 2000) gene is expressed under tissue specific promoters. Crossing these animals to conventional reporter mice such as the R26R mice produces a chimera where all the marker-expressing cells and their progeny are labeled with a single color (Fig. 5A). Extending this approach, if chimeras are generated within cre expressing cells (Zong etal., 2005; Livet et al., 2007), it is possible to trace the lineage of the labeled cell more precisely, and to observe the direction of migration and proliferation of the progeny of the initially labeled cells (Fig. 5B).

In the case of multicolor chimeric mice, when a cell cluster is derived from a limited number of progenitors, it may not express all possible colors encoded in the chimeric mouse (Fig. 6) (Ueno, in preparation) (Ueno et al., 2009). The phenomenon of "fewer color" tissues should be more frequently observed in two situations: (1) A smaller number of progenitors generate the tissue. (2) More colors are used to generate the chimeras (Ueno, in preparation). Assuming that the tissue includes more than one lineage of cells and the tissue is not supplied by cells from outside the tissue of interest, the phenomenon could be used for lineage tracing of the cells within the tissue. Fig. 7 shows a diagrammatic illustration of one progenitor population giving rise to two lineages of cells, $A$ and $B$. If these two lineages of cells are derived from a small number of cells within the founder population, they could lose one or more colored cells. If the cell type $A$ and $B$ are generated independently, the combination of colors they have will generally be different (they will sometimes be the same by statistical chance). If the two lineages of cells share the same direct progenitors within the founder cells, they generally have the same combination of colors. The basic rule is the cells never get colors that the founder cells do not have, while they can lose some of the colors of founder cells. To draw definitive conclusions we generally need to check a sufficient number of samples combined with statistical analyses. In this way, we can draw a hierarchical map of generation of tissues (Ueno, in preparation).

\section{Yolk sac hematopoiesis and adult hematopoiesis}

\section{Yolk sac hematopoiesis}

In mammals, blood and endothelial cells are the first differentiated cell types that are generated in the early stage embryo. In mice, they appear by E7.25 - 7.5 within the extra-embryonic yolk sac as a cluster surrounded by endothelial cells called blood islands(Haar and Ackerman, 1971a, Haar and Ackerman, 1971b). Blood circulation is established by approximately E8.25 in mice (McGrath et al., 2003). The hematopoiesis in yolk sac is called primitive hematopoiesis, and it has a distinct feature from that in intra-embryonic, adult type hematopoiesis. In the yolk sac hematopoiesis, blood cells are largely composed of nucleated erythrocytes that carry embryonic and fetal type hemoglobins.

\section{Development of blood cells from mesodermal progenitors}

In the case of mouse, epiblast cells before E5.5 have a multipotency to generate any lineage of cells in embryo proper,

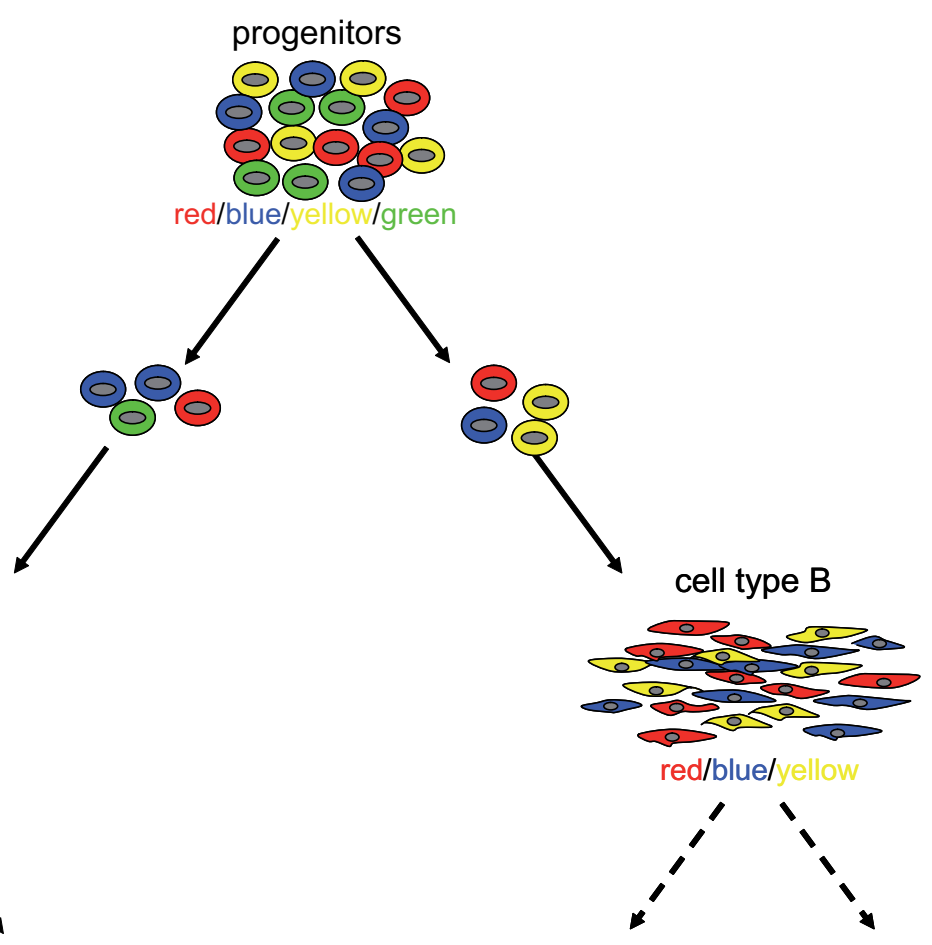
contribute to any lineage of somatic and germ cells (Gardner and Rossant, 1979; Lawson et al., 1991). Then, during gastrulation, three germ layers are generated (Tam and Behringer, 1997). The first mesodermal cells emerge at the early streak stage (E6.5), and are reported to give rise to embryonic and extraembryonic mesoderm (Lawson and Pedersen, 1992; Tam and Behringer, 1997). The fate mapping studies of the pre-streak stage epiblast have demonstrated that the progenitors of yolk sac blood islands exist within the distal proximal portion of the primitive streak and that commitment to these progenitors begins as early as the mid streak stage (Kinder et al., 1999; Lawson et al., 1991; Palis et al., 1999) (Fig. 8A). The progenitors then migrate to the extraembryonic yolk sac. As described, the first blood island appears in the yolk sac at the neural plate stage (E7.25-7.5) (Haar and Ackerman, 1971a, Haar and Ackerman, 1971b).

\section{Origin of adult HSCs in yolk sac blood islands or embryo proper?}

The question of whether primitive hematopoietic cells in the yolk sac and definitive hematopoietic cells that subsequently

TABLE 1

\section{CHIMERIC ANALYSIS OF SPLEEN COLONIES}

\begin{tabular}{lccc} 
Cells & \multicolumn{3}{c}{ Antiserum } \\
\hline & Anti D & Anti K & NMS \\
\cline { 2 - 4 } AKR & 2,4 & 61,9 & 2,7 \\
BALB/c & 89,7 & 2,6 & 0,6 \\
C57BL & 3,7 & 4,4 & 6,2 \\
Spleen colonies \#1 & 88 & 71,4 & 2,4 \\
Spleen colonies \#2 & 91,9 & 55,3 & 8,2 \\
\hline
\end{tabular}

From Weissman et al. (1977). 
appear in the embryo proper share a common origin or not has been a subject of debate for many years.

Moore and Metcalf showed that the precirculation mouse yolk sac contained hematopoietic progenitors that could be read out either by in vitro colony assays (Moore and Metcalf, 1970), or by the generation of day 10 spleen colonies using the method of Till and McCulloch (Becker etal., 1963). In 1977 and 1978 Weissman, Papiouannou and Gardner isolated genetically defined donor blood cells from precirculation or just post-circulation mouse yolk sacs, and transplanted them in utero to the yolk sac cavities of synchronic allogeneic embryos (Weissman etal., 1977; Weissman et al., 1978). These mice were chimeric for life in both the myeloerythroid and the lymphoid lineages. Donor day 10 spleen colony forming cells were present in the bone marrow of chimeric hosts; while day 10 spleen CFU were once thought to be the product of HSC, we now know that HSC give colonies days 12-14, and the vast majority of day 10 spleen colonies are formed from injected hematopoietic CMP and MEP (Fig. 9). Because neither CMP nor MEP self-renew, their continued presence requires the persistence of self-renewing HSC. Fig. 9 gives the general method of testing these mice, and Tables 1 and 2 are a summary of those experiments, performed in 1975. Thus it was established that the yolk sac can contribute to adult hematopoiesis by in vivo experimentation.

Then, it was proposed later that adult hematopoietic cells are generated in the embryo proper independently from yolk sac blood cells. Intraembryonic hematopoietic cells are first observed in the paraaortic splanchnopleura (P-Sp) region at E8.5 (Cumano etal., 2001), and multipotent progenitors are first generated in the aorta-gonad-mesonephros (AGM) region at around E10.5 (Medvinsky and Dzierzak, 1996). Primitive type nucleated erythrocytes generated in the extraembryonic yolk sac disappear during the fetal period. Moreover, hematopoietic cells in yolk sac
A
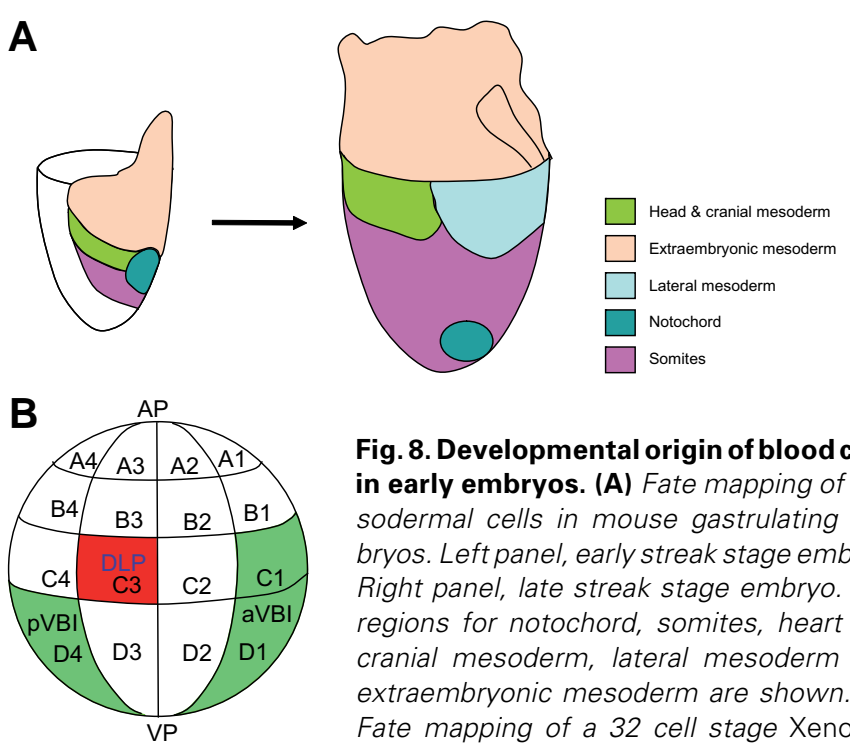

Fig. 8. Developmental origin of blood cells in early embryos. (A) Fate mapping of mesodermal cells in mouse gastrulating embryos. Left panel, early streak stage embryo; Right panel, late streak stage embryo. The regions for notochord, somites, heart and cranial mesoderm, lateral mesoderm and extraembryonic mesoderm are shown. (B) Fate mapping of a 32 cell stage Xenopus embryo. aVBI, anterior ventral blood islands; $p V B I$, posterior ventral blood islands; $D L P$, dorsal lateral plate; $A P$, animal pole; $V P$, vegetal pole.

before the onset of blood circulation cannot engraft in lethally irradiated adult bone marrow by transplantation. Transplantable HSCs are first generated in the AGM region at $~ E 10.5$. This finding indicates that "primitive" hematopoietic cells in yolk sac and "definitive" hematopoietic cells that appear in the AGM are qualitatively different, potentially implying that they are generated separately. Oddly, the PAS cells when cultured in vitro show progenitor, but not fully multipotent stem cell activity(Cumano et al., 2001) (Medvinsky and Dzierzak, 1996); this is consistent with their origin at a distant site, as it is without precedent that progenitors can be derived from mesoderm directly rather than via

TABLE 2

DIRECT AND SPLEEN COLONY ANALYSIS OF LITTERS FOR HEMATOPOIETIC PLURIPOTENT STEM CELL CHIMERISM

\begin{tabular}{|c|c|c|c|c|c|c|c|c|c|}
\hline \multirow[b]{3}{*}{ Mouse \# } & \multicolumn{7}{|c|}{ 1st transplant of donor yolk-sac blood island hematopoietic cells } & \multicolumn{2}{|c|}{ 2nd transplant of Host-1 bone marrow cells } \\
\hline & \multicolumn{2}{|c|}{$\begin{array}{l}\text { Source of yolk-sac cells } \\
\text { (Donor) }\end{array}$} & \multicolumn{3}{|c|}{ Host-1 } & \multicolumn{2}{|c|}{ Donor-derived cells in Host-1 } & \multicolumn{2}{|r|}{ Host-2 } \\
\hline & $\mathrm{H}-2$ & age (dpc) & $\mathrm{H}-2$ & age (dpc) & $\begin{array}{c}\text { Sacrifice age } \\
\text { (days after birth) }\end{array}$ & Thymus & Bone Marrow & $\mathrm{H}-2$ & $\begin{array}{l}\text { Original donor-derived } \\
\text { spleen colonies }\end{array}$ \\
\hline 1 & $d / d$ & 9 & $\mathrm{~b} / \mathrm{k}$ or $\mathrm{b} / \mathrm{b}$ & 9 & 1 & + & + & $\mathrm{d} / \mathrm{d}$ & + \\
\hline 2 & $d / d$ & 9 & $\mathrm{~b} / \mathrm{k}$ or $\mathrm{b} / \mathrm{b}$ & 9 & 1 & - & ND & $d / d$ & + \\
\hline 3 & $d / d$ & 9 & $\mathrm{~b} / \mathrm{k}$ or $\mathrm{b} / \mathrm{b}$ & 9 & - & ND & ND & $d / d$ & + \\
\hline 5 & $d / d$ & 9 & $\mathrm{~b} / \mathrm{k}$ or $\mathrm{b} / \mathrm{b}$ & 9 & - & ND & ND & $d / d$ & + \\
\hline 6 & $\mathrm{~b} / \mathrm{k}$ or $\mathrm{b} / \mathrm{b}$ & 8 & $d / d$ & 8 & 43 & + & ND & ND & ND \\
\hline 7 & $\mathrm{~b} / \mathrm{k}$ or $\mathrm{b} / \mathrm{b}$ & 8 & $d / d$ & 8 & 43 & + & ND & ND & ND \\
\hline 8 & $\mathrm{~b} / \mathrm{k}$ or $\mathrm{b} / \mathrm{b}$ & 8 & $d / d$ & 8 & 43 & - & ND & ND & ND \\
\hline 9 & $b / k$ or $b / b$ & 8 & $\mathrm{~b} / \mathrm{b}$ & 8 & 43 & + & ND & ND & ND \\
\hline 10 & $\mathrm{~b} / \mathrm{k}$ or $\mathrm{b} / \mathrm{b}$ & 8 & $\mathrm{~b} / \mathrm{b}$ & 8 & 36 & + & ND & ND & ND \\
\hline 11 & $\mathrm{~b} / \mathrm{k}$ or $\mathrm{b} / \mathrm{b}$ & 8 & $\mathrm{~b} / \mathrm{b}$ & 8 & 36 & + & ND & ND & ND \\
\hline 12 & $d / d$ & 9 & $\mathrm{~b} / \mathrm{b}$ & 8 & 36 & - & + & $d / d$ & + \\
\hline 13 & $d / d$ & 9 & $\mathrm{~b} / \mathrm{b}$ & 8 & 51 & - & + & $d / d$ & + \\
\hline 14 & $d / d$ & 9 & $\mathrm{~b} / \mathrm{b}$ & 8 & 51 & - & - & $d / d$ & + \\
\hline 15 & $b / k$ or $b / b$ & 8 & $\mathrm{~b} / \mathrm{b}$ & 9 & 43 & + & ND & ND & ND \\
\hline 16 & $\mathrm{~b} / \mathrm{k}$ or $\mathrm{b} / \mathrm{b}$ & 8 & $\mathrm{~b} / \mathrm{b}$ & 9 & 43 & - & ND & ND & ND \\
\hline 17 & $\mathrm{~b} / \mathrm{k}$ or $\mathrm{b} / \mathrm{b}$ & 8 & $\mathrm{~b} / \mathrm{b}$ & 9 & 43 & + & ND & ND & ND \\
\hline 20 & $d / d$ & 10 & $\mathrm{~b} / \mathrm{k}$ & 9 & 34 & - & + & $d / d$ & + \\
\hline 21 & $d / d$ & 10 & $\mathrm{~b} / \mathrm{k}$ & 9 & 34 & - & + & $d / d$ & + \\
\hline
\end{tabular}

From Weissman et al. (1978). 
HSC.

However, another possibile explanation is that HSCs in the AGM come from yolk sac, but undergo further maturation in the AGM niche during which time they acquire the ability to engraft in adult bone marrow. Actually past studies showed that by coculturing E8.5 yolk sac cells with AGM-derived stromal cells for 4 days, adult type HSCs that can reconstitute adult bone marrow are generated in vitro (Matsuoka et al., 2001). The signals required to induce the maturation are unknown, however, introduction of HoxB4 (Kyba et al., 2002) or Cdx4 (Wang et al., 2005) can make the yolk sac or ES derived hematopoietic cells transplantable to adult bone marrow. Since blood circulation between yolk sac and embryo proper is established as early as E8.25, it is therefore possible that the first hematopoietic activity detected in the embryo proper at paraaortic splanchnopleura (P-Sp) region at E8.5 (Cumano et al., 2001) comes from yolk sac. This conclusion needs to be tested by lineage tracing from yolk sac at E8.0 and by lineage tracing from E10.5 dorsal aorta.

Numerous attempts have been performed to answer the issue. First, as descrived above, we (Akashi and Weissman, Oxford University Press, Oxford 2001; Weissman et al., 1978) and other groups (Toles et al., 1989) have shown that by transplanting E8.0 yolk sac cells into the yolk sac cavity (Weissman et al., 1978); (Weissman et al., 1977)or transplacentally (Toles et al., 1989) to another early stage embryo, that the progeny of yolk sac blood islands injected orthotopically and synchronically contribute to lifelong hematopoiesis and lymphopoiesis. Fate-mapping studies of early mesodermal cells have been performed. By single cell

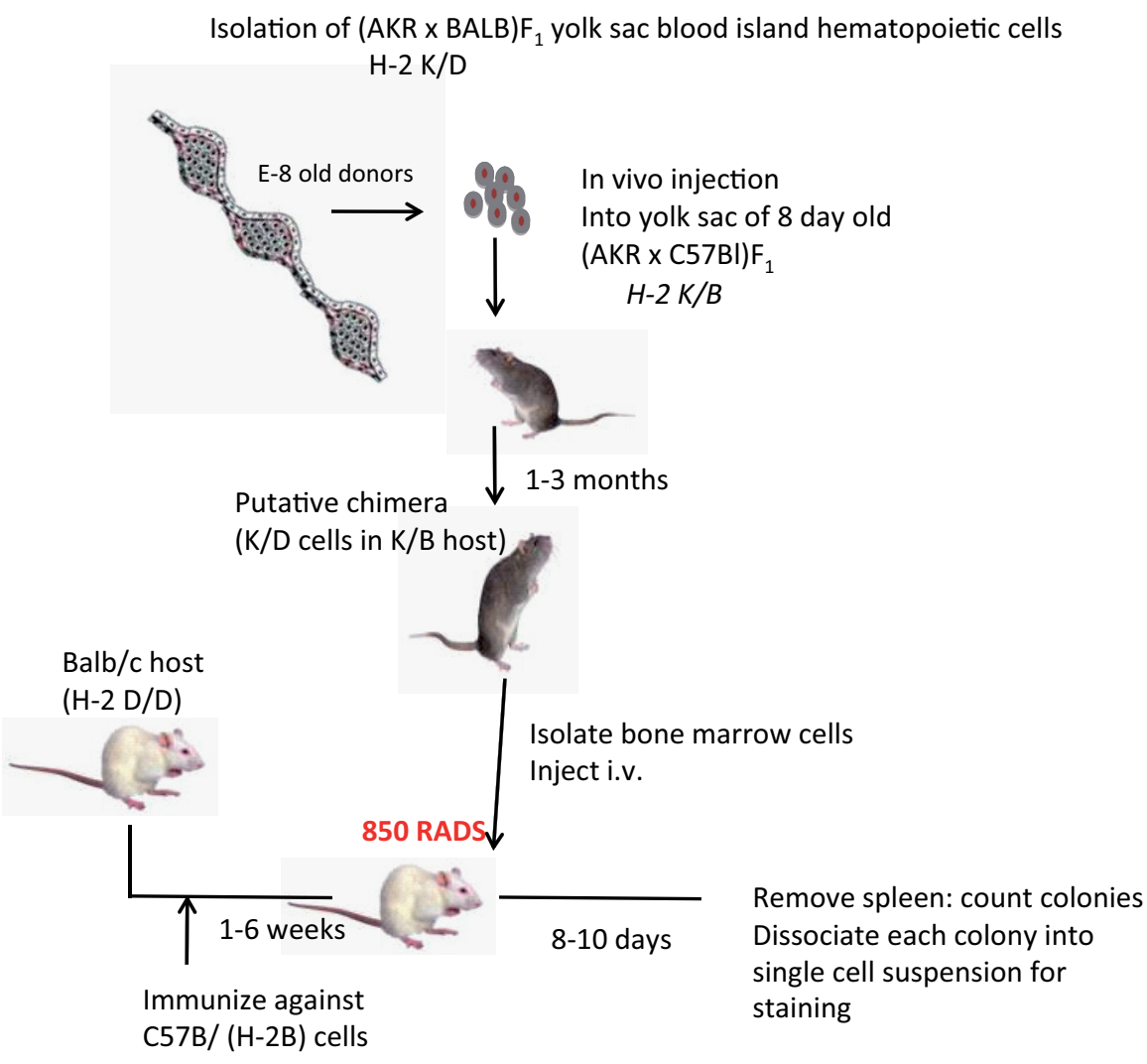

Fig. 9. Experimental design of yolk sac blood cells (Weissman et al., 1977, 1978). labeling followed by in vitroculture of embryos, it has been shown that progenitors for yolk sac hematopoietic cells are generated in the distal proximal region of primitive streak (Kinder et al., 1999; Lawson and Pedersen, 1992; Tam and Beddington, 1987) (Fig. $8 \mathrm{~A})$. It is not known in mammals whether the progenitors for AGM HSCs exist in the same region as those for yolk sac hematopoietic cells in primitive streak of gastrulating embryos. In other vertebrates, some conflicting results have been reported. By chick-toquail and chick-to-chick transplantation experiments of embryos, it has been shown that avian yolk sac cells before connecting with the embryo did not contribute to adult hematopoiesis (DieterlenLievre, 1975). In the case of non-mammalian vertebrates, it is possible to do so, and in Xenopus, it has been proposed that yolk sac and intraembryonic blood compartments originate from distinct blastomeres in the 32-cell embryo (Ciau-Uitz et al., 2000) (Fig. 8B).

Recently, in mouse, Samokfvalov et al., have performed creloxp mediated cell labeling technique to follow Runx-1 positive yolk sac cells at E7.5, before establishment of vascular connection between yolk sac and embryos, and before intraembryonic Runx-1 positive cells are generated. They showed that these yolk sac cells can contribute to adult HSCs for at least 15 months after birth (Samokhvalov et al., 2007). This result indicates that at least some adult HSCs originate from yolk sac. However, because developmental stages of embryos within littermates have some variation (Downs and Davies, 1993), whereas activation of creER driven under Runx-1 promoter by tamoxifen is simultaneous (Samokhvalov et al., 2007), further experiments are still needed (DeWitt, 2007; Ueno and Weissman, 2007; Scudellari, 2009).

\section{Lineage relationships between endot- helial and hematopoietic cells}

Another issue regarding origin of blood cells is lineage relationships between hematopoietic and endothelial cells. The concept that blood and endothelial cells share common origins was supported by histological observations that hematopoietic and endothelial cells of each blood island originate from the same population of cells, i.e., the mesodermal cell mass, and that they develop in close spatial and temporal proximity (Haar and Ackerman, 1971a, Haar and Ackerman, 1971b). Moreover, it is well known that progenitors for endothelial and hematopoietic cells share common markers e.g. Flk1 (Shalaby et al., 1997), Scl (Jaffredo et al., 2005), Imo2 (Manaia et al., 2000), Tie1 (Marshall and Thrasher, 2001), Tie2 (Takakura et al., 1998), CD31 (GarciaPorrero et al., 1998), CD34 (Wood etal., 1997). However, no common gene expression or gene knockout or knockdown study can be used to delineate lineages; they only show the importance of the gene. A further consideration is that disruption of some genes cause abnormalities in both lineages. For example, Runx 1 deficient mice have not only anemia but also 
abnormalities in their vasculature, and die mainly of bleeding during fetal life (Okuda et al., 2001; Wang et al., 1996).

\section{Hemangioblasts}

In the early 1900s, a discrete cell population that might display both hematopoietic and endothelial potential and was was discovered in chick embryo cultures (Murray, 1932; Sabin, 1920) and subsequently designated as hemangioblasts. More recent in vitro studies have shown that the differentiation of mouse embryonic stem (ES) cells into hematopoietic cells includes a clonal progenitor intermediate, the BL-CFC, that can generate both endothelial and hematopoietic cells(Choi et al., 1998; Kennedy et al., 1997). On the basis of these observations, hemangioblasts have been considered a single cell progenitor that can generate both cell lineages (Robertson et al., 1999). But even if they can generate both populations in vitro, it was not clear if the hemangioblast was the only route to either hematopoiesis or vasculogenesis in vivo.

So far, the definition of the hemangioblast is by potential and not by fate, which causes a little confusion. The BL-CFC population can give rise to blood and endothelial cells, and therefore may be considered "bipotential". However perhaps only a very small proportion of these cells give rise to both types of cells, with most of the population giving rise to either HSC or endothelial cells. In that case, it is impossible to know whether the cells that generate one cell type only are actually capable of bipotency, or whether they originate from single lineage committed progenitors. In the case of hematopoietic stem cells (HSCs), single cell transplantation experiments have clearly shown that all the bone marrow blood lineages can be generated from a single cell whereas no other fraction of progenitors can continue supplying blood cells over months. In addition, no other tissues outside of the hematolymphoid system are derived from HSC (Wagers and Weissman, 2004).To date, it has not been possible to transplant hemangioblasts in vivo in order to analyze the cell types they generate in vivo. The brief appearance of hemangioblasts during development, and the subsequent difficulty in isolating them, make the logisitics of this experiment exceedingly difficult.

It has been shown that within the brachyury and Flk1 positive fraction of the primitive streak at the mid to the late streak stage, there exist cells that possess hematopoietic and endothelial potential, thereby leading to their tentative designation as hemangioblasts (Huber et al., 2004). In studies using zebrafish embryos, single cell fate mapping has revealed that at least a proportion of the cells give rise to hematopoietic and endothelial cells (Vogeli et al., 2006), supporting the model that both lineages can originate from bipotential progenitors. One important question that remains unanswered is whether all the blood and endothelial cells originate from the hemangioblast, or whether there are separate lineage-committed progenitors that are not derived from hemangioblasts. Although there exist single cell progenitors that actually develop into endothelial and blood cells in vivo (Huber et al., 2004; Vogeli et al., 2006), the frequency of such progenitors that actually give rise to both blood and blood vessel fates in vivo is quite low. Additional experiments will be needed to fully elucidate the origin and differentiation of endothelial cells.

\section{Hemogenic endothelial cells}

In addition to hemangioblasts, there is another related issue regarding the existence and role of hemogenic endothelial cells as a shared progenitor in the endothelial and blood development pathways. These cells were first observed in experiments where blood cells were found to be generated from a subset of phenotypically differentiated endothelial cells on the wall of the embryonic aorta (Marshall and Thrasher, 2001; North et al., 1999; Tavian et al., 1999). The so-called hemogenic endothelial cells possessing hematopoietic potential are initially identified in the AGM region at around E10.5 (Jaffredo et al., 1998; North et al., 2002). Hemogenic endothelial cells have been shown to arise in cultures of in differentiating ES cell cultures (Nishikawa et al., 1998). Further support or a connection between endothelial and hematopoietic differentiation was provided by a study using dye (Ac-LDL-Dil) labeling of endothelial cells at E10, with subsequent generation of Dil positive erythrocytes, indicating that they were potentially endothelial cell-derived (Sugiyama et al., 2003). One study difficult to reconcile with this emerging view or intersecting endothelial and hematopoietic development was performed by Bertland, who identified markers for hematopoietic progenitors in the AGM region that possess activity of long-term reconstitution of sublethally irradiated mice. By using the markers (c-Kit, AA4.1, CD31, and CD41, but not Flk1, and mainly negative for CD45), they showed that the hematopoietic stem cells do not colocalize with endothelial cells but rather they exist in subaortic patches (Bertrand et al., 2005) (Fig. 8C).

To summarize these collective studies, there is evidence that hemangioblasts are established from yolk sac hematopoiesis and ES cells in vitro, whereas the existence of hemogenic endothelium has been proposed from analyses of AGM hematopoiesis. The obvious question of a potential lineage relationship between hemangioblasts and hemogenic endothelium is currently unclear. Very recently, a series of papers have proposed a model integrating both hemangioblast and hemogenic endothelium

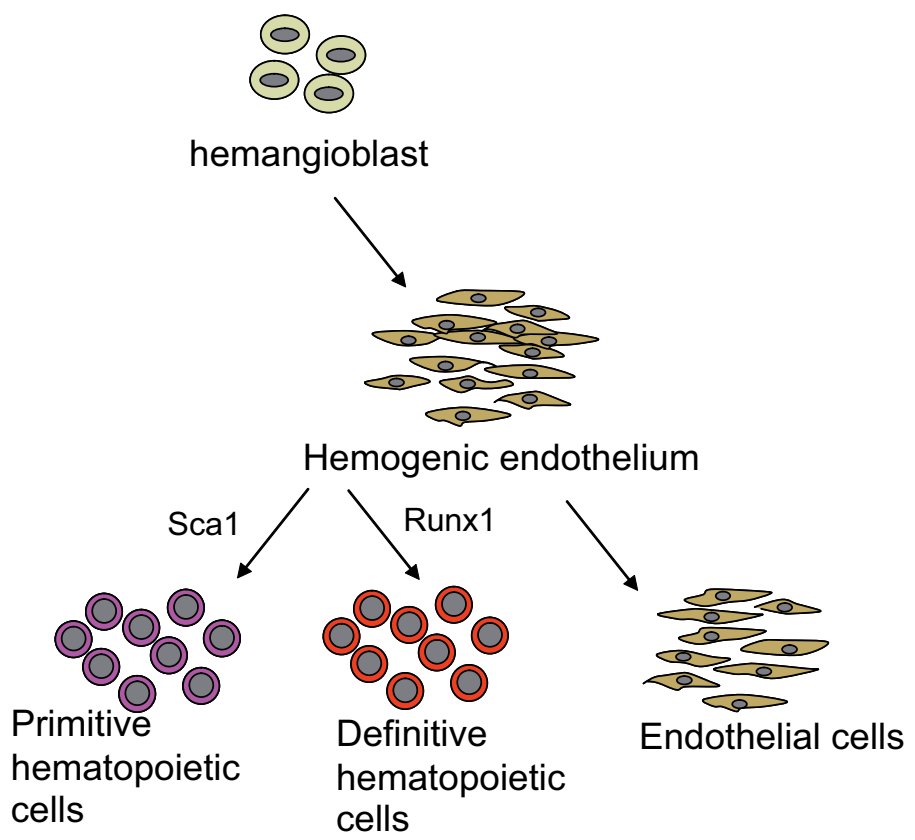

Fig. 10. Lineage relationships between hemangioblasts, hemogenic endothelium and blood/endothelial cells (Chen et al., 2009; Eilken et al., 2009; Lancrin et al., 2009). 


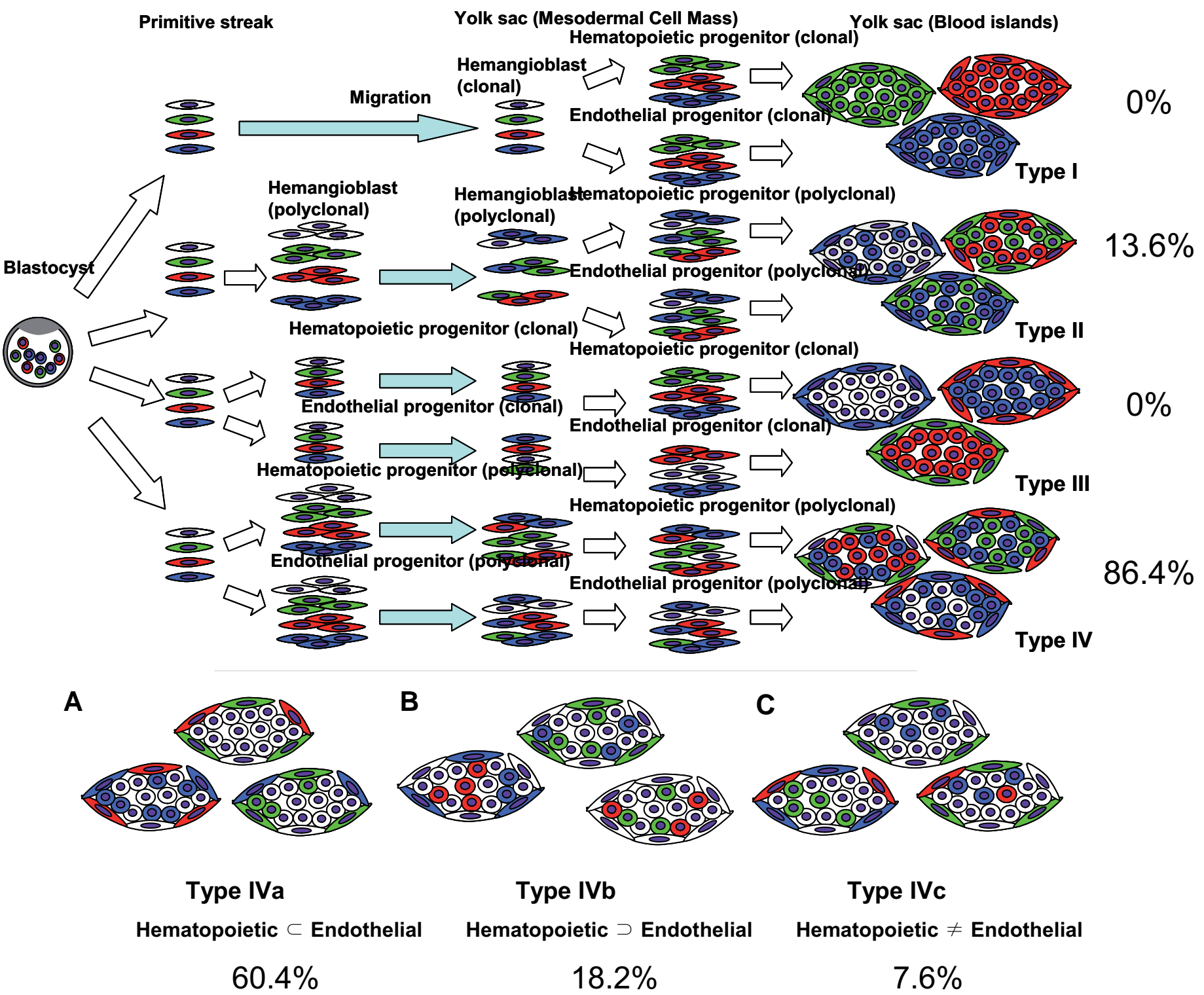

Fig. 11 (Top). Schematic of predicted results of possible yolk sac blood islands that could be obtained in this study (Ueno and Weissman, 2006).

Fig. 12 (Bottom). Subclassification of type IV blood islands. (A) If the hematopoietic cells in a particular blood island are a subgroup of fluorescence categories of those found in the endothelial cells, they are defined as type IVa. (B) If those in the endothelial cells are a subgroup of those in the hematopoietic cells, they are subclassified as type IVb. (C) If some colors do not overlap in both lineages, they are classified as type IVc.

populations(Chen et al., 2009; Eilken et al., 2009; Lancrin et al., 2009). In this new model, hemangioblasts initially generate hemogenic endothelium, which subsequently gives rise to hematopoietic cells (Fig. 10). During differentiation, ES cells generate $\mathrm{BL}-\mathrm{CFC}$, the supposed counterpart of in vitro generated hemangioblasts. BL-CFC subsequently generate $\mathrm{Tie} 2+/ \mathrm{c}-\mathrm{kit}+$ / CD41- blast colonies. The latter cells have markers of endothelial cells, and can form endothelial networks when cultured in matrigel, however they can also give rise to hematopoietic cells in vitrovia an Scl-dependent mechanism (Lancrin et al., 2009). These investigators proposed that BL-CFC differentiation into hematopoietic cells occurs via the same mechanism that governs development of primitive hematopoietic cells in yolk sac blood islands, and development of definitive hematopoietic cells in the AGM region, suggesting existence of a common mechanism for the origin of blood and endothelial cells both for primitive and definitive hematopoiesis. In another study, a new technique of live imaging at a single cell level was performed to observe this step in detail (Eilken et al., 2009). The study provided evidence that a single endothelial cell derived from BL-CFC can give rise to hematopoietic cells (Eilken et al., 2009; Lancrin et al., 2009).

The new model does not contradict the previous hemangioblast model, since both models indicate that the progeny of hemangioblasts are both endothelial and blood cells. However, the new model re-defines the hemangioblast as a cell type that does not directly give rise to blood cells but generates them through specialized intermediate progenitors that are designated hemogenic endothelium. The new model proposes that hemogenic 

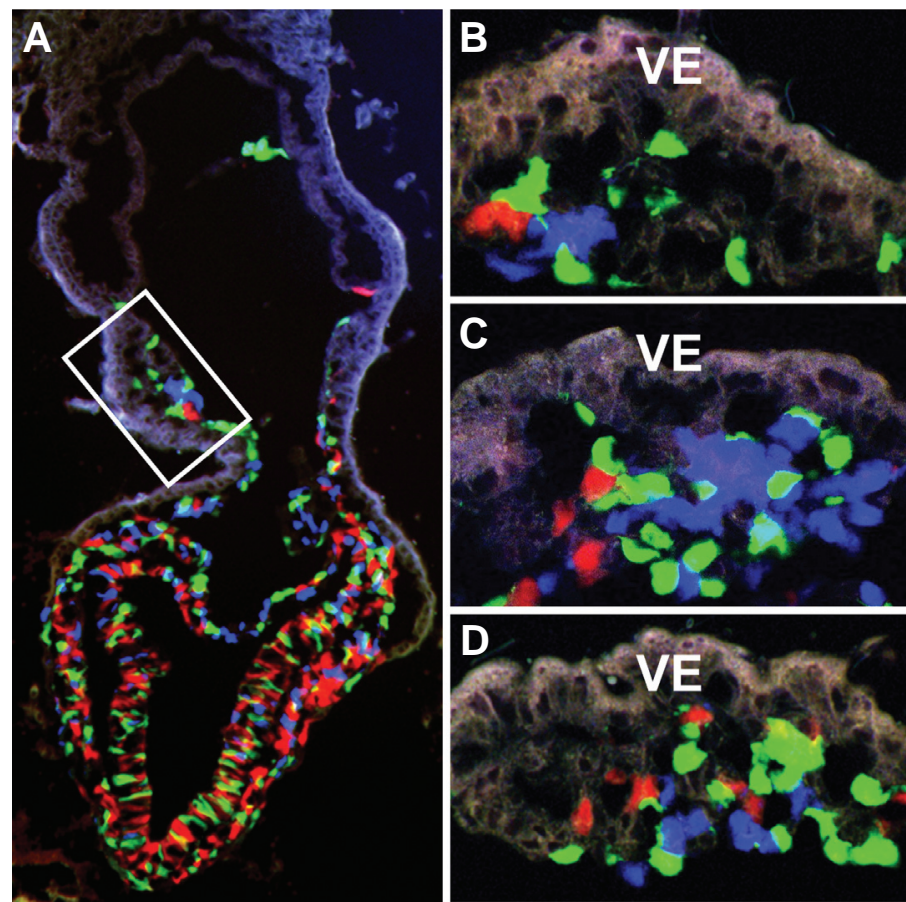

endothelium exists both in yolk sac blood islands and in the AGM region.

\section{Chimeric analysis of yolk sac blood islands}

\section{Polyclonal origin of yolk sac blood islands}

As described above, several important questions regarding origin of blood and endothelial cells remain unanswered, such as potential lineage relationships in vivo between these two juxtaposed cellular systems. Similarly the relationship between hemangioblasts and hemogenic endothelium is yet to be elucidated. To examine whether our system of complex chimeric mouse generation and associated analyses (as described above) can answer such questions, we created four-color chimeras (tetrachimeras) by injection of three different color expressing ES cells as a mixture into no-color blastocysts (Ueno et al., 2008; Ueno and Weissman, 2006). The injected ES cells were incorporated into the ICM, which gives rise to multipotent progenitors in the epiblast. These form three germ layers during gastrulation, and a part of mesoderm progenitors give rise to yolk sac blood islands, as described above. Because we don't know exactly where and when hemangioblasts and their progeny are generated, we considered several possibilities. A schematic depicting all possible results of yolk sac blood islands that could theoretically be produced in this study is provided in Figs 11 and 12 .

The results(Ueno and Weissman, 2006) clearly indicate that (1) each yolk sac blood island is polyclonal (Fig. 13) and that (2) endothelial cells and blood cells within each blood island
Fig. 13. Chimeric analysis of yolk sac blood islands with fluorescent ES clones. (A) A chimeric embryo at the early neural plate stage (EB). A white rectangle indicates an immature blood island (an arrow). Arrows indicate the direction of tissue extension. ec, embryonic ectoderm; me, intraembryonic mesoderm; ve, visceral endoderm; am, amnion; al, allantois; ch, chorion. (B,C,D) An immature blood island with EGFP, ECFP or mRFP1 expressing and non-fluorescent progenitor cells. (B) This picture is a magnified picture of $(A)$, white rectangle.

generally have a distinct combination of colors (Fig. 14), suggesting that they arise independently before they reach the yolk sac membrane. Decreasing the degree of chimerism by single cell injection further segregated the contribution of blood and endothelial cells to each blood island. Approximately $80-85 \%$ of blood islands were type IV blood islands (Fig. 11), while 13-18\% are type II (Ueno and Weissman, 2006). These data have been added to Fig. 11 (percentage values on left side of schematic) for clarity. In single cell injection experiments, we frequently observed blood islands in which marker-expressing cells only contributed to endothelial cells or blood cells, and in these cases blood islands with the same combination of colored cells tended to exist in succession (Fig. 15). Collectively, these results suggest that (1) multiple progenitors contribute to form blood islands, that (2) blood and endothelial progenitor cells arise independently before they reach at the yolk sac membrane, and that (3) blood islands divide as the yolk sac membrane grows until they fuse together to form the vasculature on the yolk sac membrane (Fig. 15F).

\section{Progenitor cells that exclusively take endothelial fate}

Because it is possible that blood cells can migrate to nearby blood islands even if they are separated by endothelial cells, it is clearer to check the combination of colors that total endothelial and total blood cells within an embryo (whole embryo analysis). The results indicate that there are many examples in which some color(s) are exclusively distributed in endothelial cells that are not found in blood cells within the same embryo (Fig. 16C). This means that progenitor cells exist that are exclusively committed to an endothelial cell fate. Of course, it could be argued that the progenitors could also be hemangioblasts, because they are defined by their potential but not by their actual fate.

Are the results shown in Figs 11-16 consistent with the new
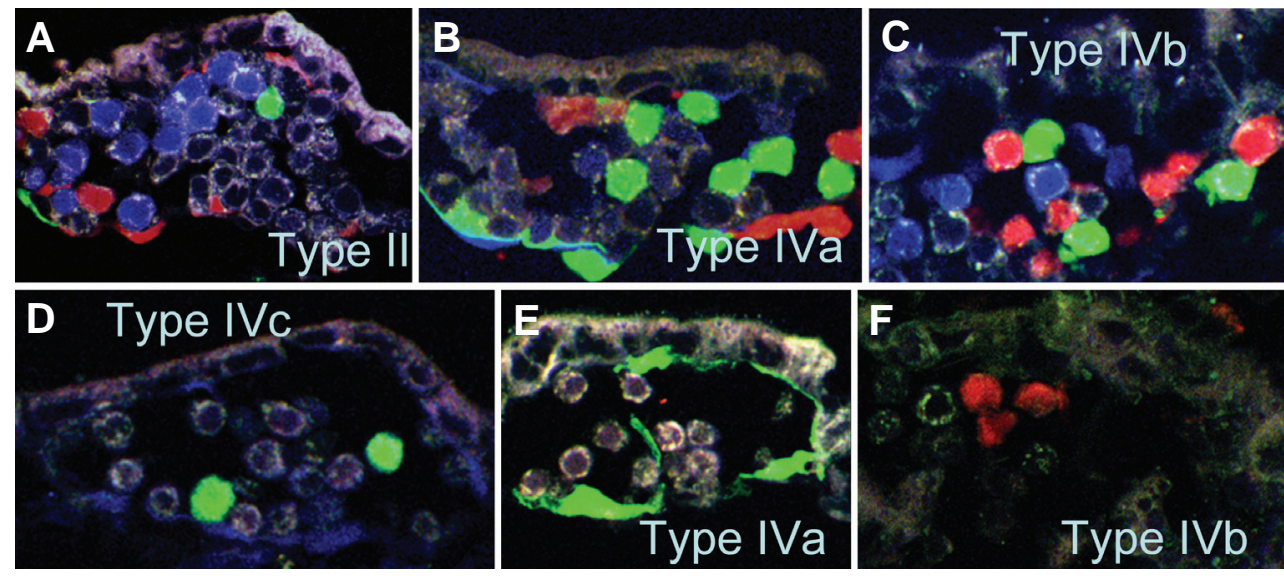

Fig. 14. Examples of chimeric blood islands. Type II, Type IVa-c blood islands are classified as shown in Figs. 10 and 11. 
model of hemangioblasts and hemogenic endothelium described in Section 3.1 i.e. that ES cells give rise to hemangioblasts, which then differentiate into hemogenic endothelial cells, a progenitor population capable of giving rise to both blood cells and endothelial cells? The Tie2+/ckit+/CD41- hemogenic endothelium exists within E7.75 immature blood islands (Lancrin et al., 2009) and a subset of them should give rise to blood cells. If this is the case, the results of blood islands in our model should be type II or type IVa (refer to Fig. 11 and 12). As shown in Section 4-1, approximately $80 \%$ of blood islands are within these categories (refer to Figs 12 and 13). The remaining blood islands observed in our experiment i.e. type IVb and type IVc blood islands, do not fit with the model (Fig. 12). The whole embryo analysis of Fig. 16C matches with the model that a subset of endothelial cells can give rise to blood cells. Therefore, our results might match with the model that blood/endothelial progenitors (hemangioblasts) first give rise to endothelial progenitors a subset of which generates hematopoietic cells while the rest becomes committed to an endothelial fate. However, we also carried out fate-mapping studies by injecting onto blastocysts ES cells marked by flk1 Cre recombination of constructs with gene loss of lacZ upon recombination, and gene expression gain of EGFP or ECFP or a 3 color vector designed to distinguish between low or no fkl1 cre expression, or low to mid level, or high level. In all cases all endothelial
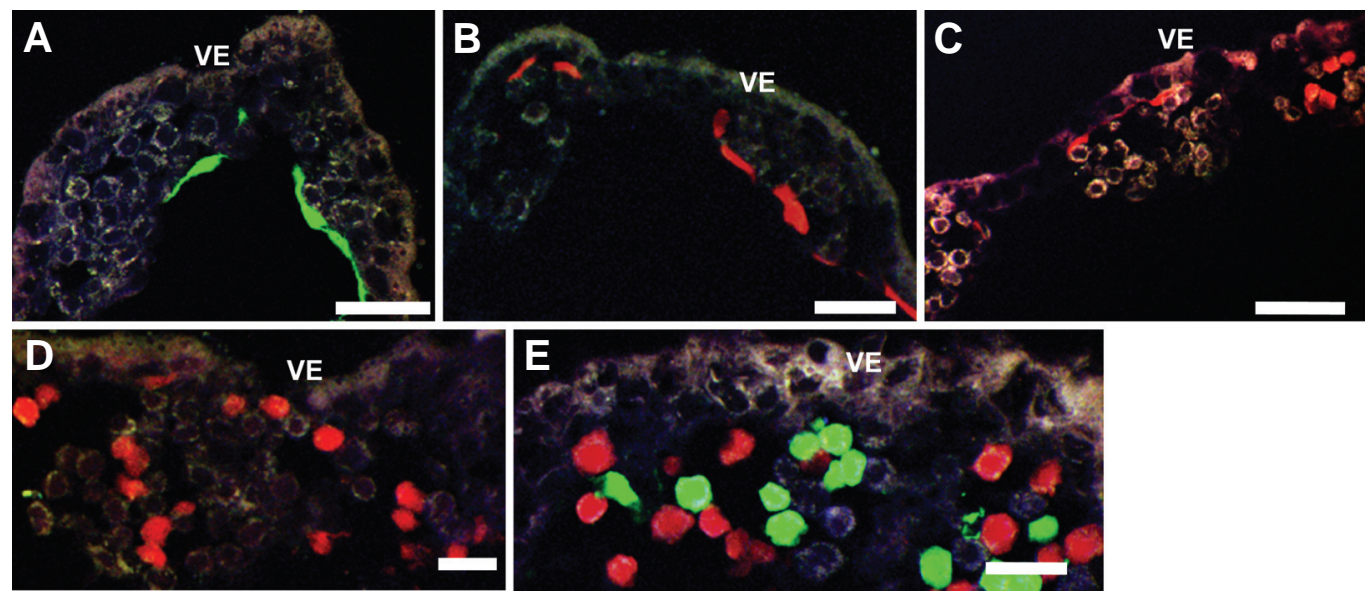

F
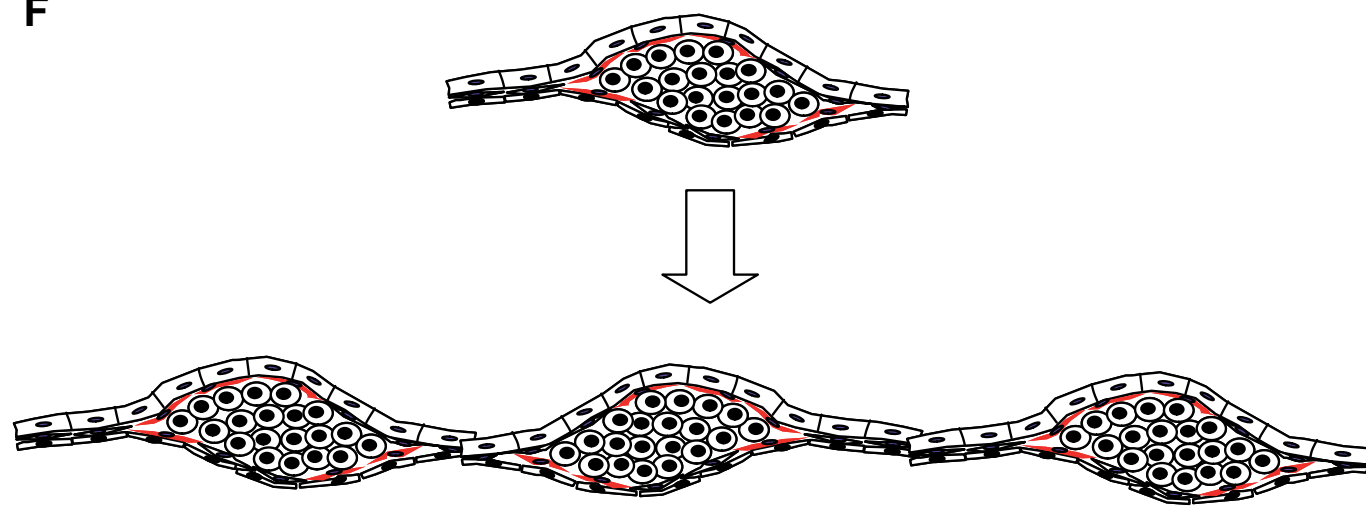

Fig. 15. Examples of chimeric blood islands obtained by single cell injection of ES cells into blastocysts. (A-C) Examples of blood islands in which fluorescent ES derived cells only contribute to endothelial cells. (D,E) Examples of blood islands in which marker-expressing cells are mainly observed in blood cells. (F) A model of division of blood islands during presomite stage embryos. cells were flk1-derived, whereas again $<20 \%$ of blood cells went through a flk1+progenitor (Ueno and Weissman, 2006). Because the produced endothelial cells were all marked as derived from a $\mathrm{flk} 1+$ and not flk1-precursor, we must think that the proposed hemogenic endothelium should have been marked, and any blood cells derived from them. Thus our data support the notion that endothelial and blood progenitors arise independently before they reach the yolk sac membrane; the vast majority of these blood cells are derived from Flk1-low/negative progenitors, while some are derived from flk1+ progenitors(Ueno and Weissman, 2006), suggesting a dual origin of blood cells. However, a recent study from another group has reported that both primitive and definitive blood cells are derived from flk-1 positive precursors, and this issue will require further investigation (Lugus et al., 2009).

\section{Future directions}

In this review, we have discussed current issues concerning the developmental origin of hematopoiesis. We have also described in considerable detail the use of mosaic or chimeric mice to help resolve these issues. The use of chimeric mice for genetic analyses was initially developed in the 1960's, however at that time the technology was not sufficiently sensitive to be used in developmental studies or to track all cells in a tissue or organ.

Recent improvements of this technology have enabled an increase in the number of colors expressed within a single mouse chimera, with a resultant increase in analytical sensitivity and genetic discrimination, enabling new applications of the approach. Indeed, it was only with the development of tetrachimeras that every cell in a tissue such as intestine can be marked, and in those clonal intestinal domains cell in the lamina propria, the mesothelium, and the surrounding capsule are made up of mixtures of all four colors (Ueno, in preparation).

Here we summarize in this review recent studies from our laboratory which demonstrate that increasing the number of colors expressed by a single chimeric/mosaic mouse enables application of this technology to cell lineage tracing. Our experiments have already yielded important new information, however further technology evolution is required to remove ambiguity of the coincident versus disparate origin of like colored cells that can result from the random labeling pro- 
A

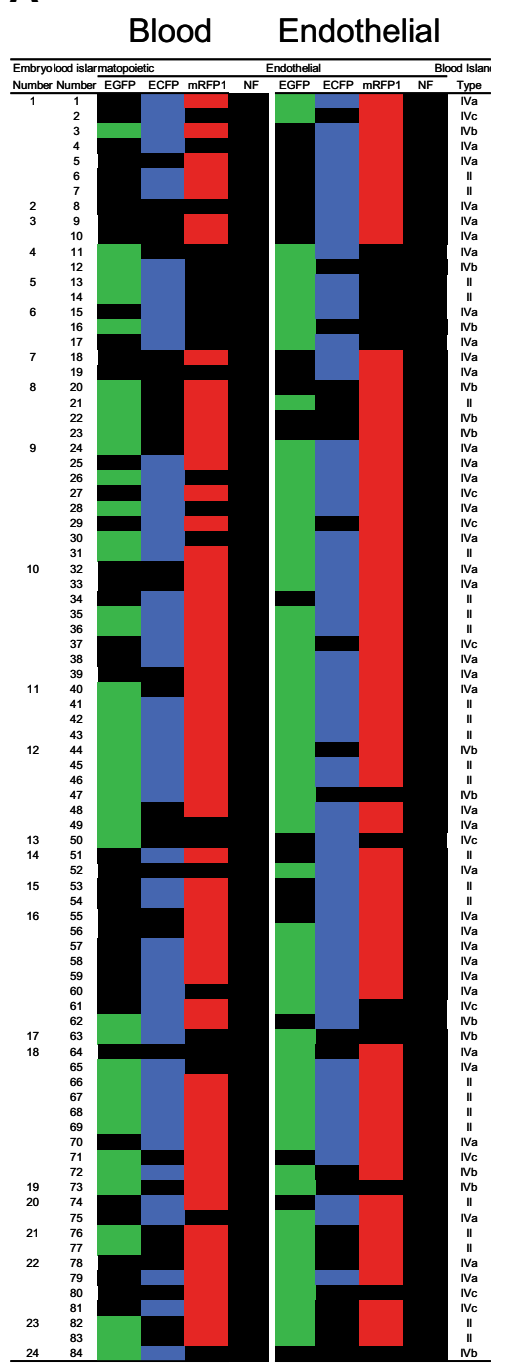

B

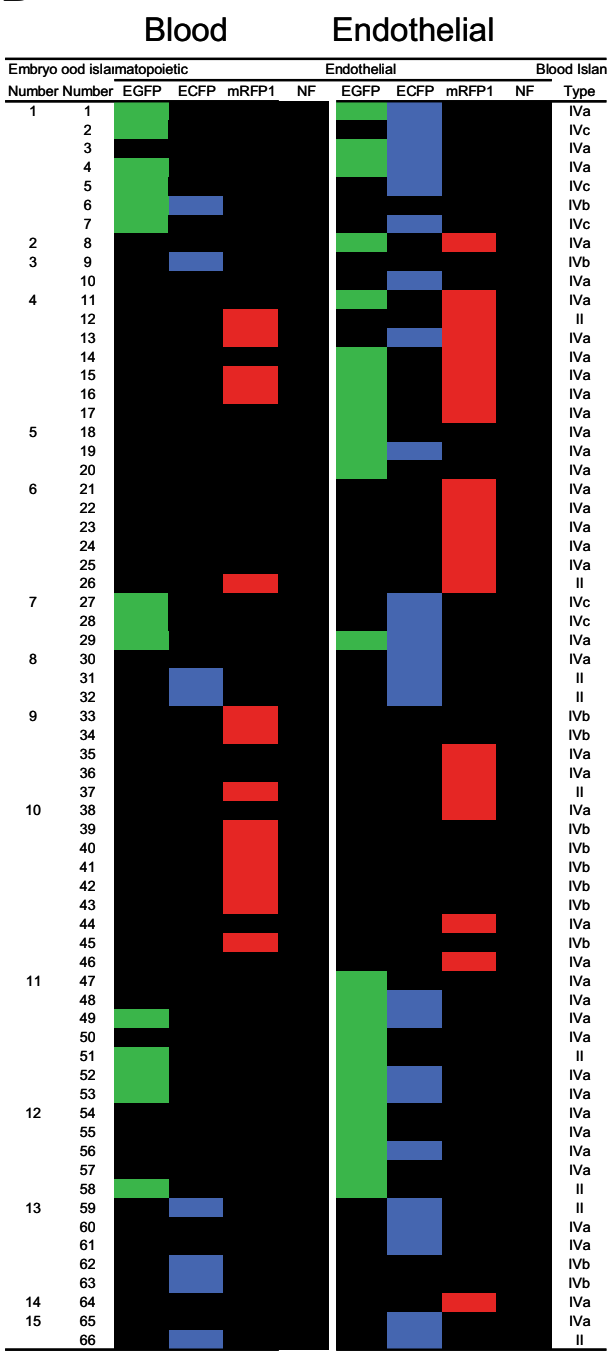

C

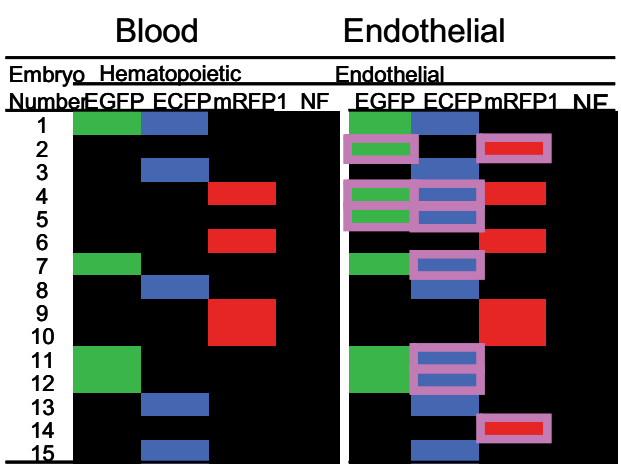

Hematopoietic $\subset$ Endothelial cedures in current use. Future development of this technology will likely combine it with the cre-ER-T $\mathrm{T}_{2}$-mediated cell labeling, creating mosaic tissues that are gene and/or tissue specific, and inducible at distinct stages of development. In addition, by changing the dose of locally administered tamoxifen, the degree of recombination in these complex chimeras can be adjusted, and perhaps microinfusion of tamoxifen can limit lineage marking in both time and place. Modifications of this nature will likely augment our abilities to trace lineages and elucidate lineage relationships during cell development in the otherwise unmanipulated host, and enable a more comprehensive understanding of how blood cells evolve from the most primitive totipotent cells in the developing embryo.

\section{References}

AKASHI, K. and WEISSMAN, I.L. (2001). Stem Cells and hematolymphoid development. In Hematopoiesis: A developmental approach (Ed. Zon LI). Oxford University Press, Oxford, pp. 115-134.

BECKER, A.J., MC, C.E. and TILL, J.E. (1963). Cytological demonstration of the clonal nature of spleen colonies derived from transplanted mouse marrow cells. Nature 197: 452-454.
BERTRAND, J.Y., GIROUX, S., GOLUB, R., KLAINE, M., JALIL, A., BOUCONTET L., GODIN, I. and CUMANO, A. (2005). Characterization of purified intraembryonic hematopoietic stem cells as a tool to define their site of origin. Proc Nat/ Acad SCI U S A 102: 134-139.

CHEN, M.J., YOKOMIZO, T., ZEIGLER, B.M., DZIERZAK, E. and SPECK, N.A (2009). Runx 1 is required for the endothelial to haematopoietic cell transition but not thereafter. Nature 457: 887-891.

CHOI, K., KENNEDY, M., KAZAROV, A., PAPADIMITRIOU, J.C. and KELLER, G. (1998). A common precursor for hematopoietic and endothelial cells. Develop ment 125: 725-732.

CIAU-UITZ, A., WALMSLEY, M. and PATIENT, R. (2000). Distinct origins of adult and embryonic blood in Xenopus. Cel/102: 787-796.

CUMANO, A., FERRAZ, J.C., KLAINE, M., DI SANTO, J.P. and GODIN, I. (2001). Intraembryonic, but not yolk sac hematopoietic precursors, isolated before circulation, provide long-term multilineage reconstitution. Immunity 15: 477485.

DEWITT, N. (2007). Rewriting in blood: blood stem cells may have a surprising origin. Nat Rep Stem Cells doi: 0.1038/stemcells.2007.42

DIETERLEN-LIEVRE, F. (1975). On the origin of haemopoietic stem cells in the avian embryo: an experimental approach. J Embryol Exp Morpho/33: 607-619.

DOWNS, K.M. and DAVIES, T. (1993). Staging of gastrulating mouse embryos by morphological landmarks in the dissecting microscope. Development 118: 1255-1266. 
EILKEN, H.M., NISHIKAWA, S. and SCHROEDER, T. (2009). Continuous singlecell imaging of blood generation from haemogenic endothelium. Nature 457: 896-900.

EVANS, M.J. and KAUFMAN, M.H. (1981). Establishment in culture of pluripotential cells from mouse embryos. Nature 292: 154-156.

GARCIA-PORRERO, J.A., MANAIA, A., JIMENO, J., LASKY, L.L., DIETERLENLIEVRE, F. and GODIN, I.E. (1998). Antigenic profiles of endothelial and hemopoietic lineages in murine intraembryonic hemogenic sites. Dev Comp Immuno/22: 303-319.

GARDNER, R.L. (1968). Mouse chimeras obtained by the injection of cells into the blastocyst. Nature 220: 596-597.

GARDNER, R.L. (1978). Production of chimeras by injecting cells or tissue into the blastocyst. Methods in Mammalian Reproduction (ed. J. C. Daniel, M37-165.

GARDNER, R.L. and ROSSANT, J. (1979). Investigation of the fate of 4-5 day postcoitum mouse inner cell mass cells by blastocyst injection. J Embryol Exp Morpho/52: 141-152.

HAAR, J.L. and ACKERMAN, G.A. (1971a). A phase and electron microscopic study of vasculogenesis and erythropoiesis in the yolk sac of the mouse. Anat. Rec. 170: 199-223.

HAAR, J.L. and ACKERMAN, G.A. (1971b). Ultrastructural changes in mouse yolk sac associated with the initiation of vitelline circulation. Anat. Rec. 170: 437455.

HUBER, T.L., KOUSKOFF, V., FEHLING, H.J., PALIS, J. and KELLER, G. (2004). Haemangioblast commitment is initiated in the primitive streak of the mouse embryo. Nature 432: 625-630.

IMAI, T., JIANG, M., CHAMBON, P. and METZGER, D. (2001). Impaired adipogenesis and lipolysis in the mouse upon selective ablation of the retinoid $X$ receptor alpha mediated by a tamoxifen-inducible chimeric Cre recombinase (CreERT2) in adipocytes. Proc Nat/ Acad Sci U S A 98: 224-228.

JAFFREDO, T., BOLLEROT, K., SUGIYAMA, D., GAUTIER, R. and DREVON, C. (2005). Tracing the hemangioblast during embryogenesis: developmental relationships between endothelial and hematopoietic cells. Int J Dev Bio/49: 269277.

JAFFREDO, T., GAUTIER, R., EICHMANN, A. and DIETERLEN-LIEVRE, F. (1998). Intraaortic hemopoietic cells are derived from endothelial cells during ontogeny. Development 125: 4575-4583.

KENNEDY, M., FIRPO, M., CHOI, K., WALL, C., ROBERTSON, S., KABRUN, N. and KELLER, G. (1997). A common precursor for primitive erythropoiesis and definitive haematopoiesis. Nature 386: 488-493.

KINDER, S.J., TSANG, T.E., QUINLAN, G.A., HADJANTONAKIS, A.K., NAGY, A. and TAM, P.P. (1999). The orderly allocation of mesodermal cells to the extraembryonic structures and the anteroposterior axis during gastrulation of the mouse embryo. Development 126: 4691-4701.

KRAUSE, D.S., THEISE, N.D., COLLECTOR, M.I., HENEGARIU, O., HWANG, S., GARDNER, R., NEUTZEL, S. and SHARKIS, S.J. (2001). Multi-organ, multilineage engraftment by a single bone marrow-derived stem cell. Cel/105: 369377.

KYBA, M., PERLINGEIRO, R.C. and DALEY, G.Q. (2002). HoxB4 confers definitive lymphoid-myeloid engraftment potential on embryonic stem cell and yolk sac hematopoietic progenitors. Ce//109: 29-37.

LANCRIN, C., SROCZYNSKA, P., STEPHENSON, C., ALLEN, T., KOUSKOFF, V. and LACAUD, G. (2009). The haemangioblast generates haematopoietic cells through a haemogenic endothelium stage. Nature 457: 892-895.

LAWSON, K.A., MENESES, J.J. and PEDERSEN, R.A. (1991). Clonal analysis of epiblast fate during germ layer formation in the mouse embryo. Development 113: 891-911.

LAWSON, K.A. and PEDERSEN, R.A. (1992). Early mesoderm formation in the mouse embryo. In Formation and Differentiation of Early Embryonic Mesoderm (Ed. R. Bellairs). Plenum Press, New York, pp. 33-46.

LEWIS, J.H., SUMMERBELL, D. and WOLPERT, L. (1972). Chimaeras and cell lineage in development. Nature 239: 276-279.

LI, M., INDRA, A.K., WAROT, X., BROCARD, J., MESSADDEQ, N., KATO, S., METZGER, D. and CHAMBON, P. (2000). Skin abnormalities generated by temporally controlled RXRalpha mutations in mouse epidermis. Nature 407: 633-636.
LIVET, J., WEISSMAN, T.A., KANG, H., DRAFT, R.W., LU, J., BENNIS, R.A., SANES, J.R. and LICHTMAN, J.W. (2007). Transgenic strategies for combinatorial expression of fluorescent proteins in the nervous system. Nature 450: 56 62.

LUGUS, J.J., PARK, C., MA, Y.D. and CHOI, K. (2009). Both primitive and definitive blood cells are derived from Flk-1+ mesoderm. Blood 113: 563-566.

MANAIA, A., LEMARCHANDEL, V., KLAINE, M., MAX-AUDIT, I., ROMEO, P., DIETERLEN-LIEVRE, F. and GODIN, I. (2000). Lmo2 and GATA-3 associated expression in intraembryonic hemogenic sites. Development 127: 643-653.

MARSHALL, C.J. and THRASHER, A.J. (2001). The embryonic origins of human haematopoiesis. Br J Haemato/112: 838-850.

MARTIN, G.R. (1981). Isolation of a pluripotent cell line from early mouse embryos cultured in medium conditioned by teratocarcinoma stem cells. Proc Nat/ Acad SciUS A 78: 7634-7638.

MATSUOKA, S., TSUJI, K., HISAKAWA, H., XU, M., EBIHARA, Y., ISHII, T., SUGIYAMA, D., MANABE, A., TANAKA, R., IKEDA, Y. etal. (2001). Generation of definitive hematopoietic stem cells from murine early yolk sac and paraaortic splanchnopleures by aorta-gonad-mesonephros region-derived stromal cells. Blood 98: 6-12.

MCGRATH, K.E., KONISKI, A.D., MALIK, J. and PALIS, J. (2003). Circulation is established in a stepwise pattern in the mammalian embryo. Blood 101: 16691676.

MCLAREN, A. (1972). Numerology of development. Nature 239: 274-276.

MEDVINSKY, A. and DZIERZAK, E. (1996). Definitive hematopoiesis is autonomously initiated by the AGM region. Cel/86: 897-906.

MOORE, M.A. and METCALF, D. (1970). Ontogeny of the haemopoietic system: yolk sac origin of in vivoand in vitrocolony forming cells in the developing mouse embryo. Br J Haemato/ 18: 279-296.

MURRAY, P.D.F. (1932). The development in vitro of the blood of the early chick embryo. Proc. R. Soc. London 111: 497-521.

NISHIKAWA, S.I., NISHIKAWA, S., KAWAMOTO, H., YOSHIDA, H., KIZUMOTO, M., KATAOKA, H. and KATSURA, Y. (1998). In vitro generation of lymphohematopoietic cells from endothelial cells purified from murine embryos. Immunity 8: 761-769.

NORTH, T., GU, T.L., STACY, T., WANG, Q., HOWARD, L., BINDER, M., MARINPADILLA, M. and SPECK, N.A. (1999). Cbfa2 is required for the formation of intra-aortic hematopoietic clusters. Development 126: 2563-2575.

NORTH, T.E., DE BRUIJN, M.F., STACY, T., TALEBIAN, L., LIND, E., ROBIN, C. BINDER, M., DZIERZAK, E. and SPECK, N.A. (2002). Runx1 expression marks long-term repopulating hematopoietic stem cells in the midgestation mouse embryo. Immunity 16: 661-672.

NOVELLI, M.R., WILLIAMSON, J.A., TOMLINSON, I.P., ELIA, G., HODGSON, S.V., TALBOT, I.C., BODMER, W.F. and WRIGHT, N.A. (1996). Polyclonal origin of colonic adenomas in an XO/XY patient with FAP. Science 272: 1187 1190.

OKUDA, T., NISHIMURA, M., NAKAO, M. and FUJITA, Y. (2001). RUNX1/AML1: a central player in hematopoiesis. Int $J$ Hemato/74: 252-257.

PALIS, J., ROBERTSON, S., KENNEDY, M., WALL, C. and KELLER, G. (1999). Development of erythroid and myeloid progenitors in the yolk sac and embryo proper of the mouse. Development 126: 5073-5084.

PONDER, B.A., SCHMIDT, G.H., WILKINSON, M.M., WOOD, M.J., MONK, M. and REID, A. (1985). Derivation of mouse intestinal crypts from single progenitor cells. Nature 313: 689-691.

ROBERTSON, S., KENNEDY, M. and KELLER, G. (1999). Hematopoietic commitment during embryogenesis. Ann. N. Y. Acad. Sci. 872: 9-16.

SABIN, F.R. (1920). Studies on the origin of blood vessels and of red corpuscules as seen in the liveing blastoderm of the chick during the second day of incubation: contributions to embryology. Contrib Embryo/9: 213-262.

SAMOKHVALOV, I.M., SAMOKHVALOVA, N.I. and NISHIKAWA, S. (2007). Cell tracing shows the contribution of the yolk sac to adult haematopoiesis. Nature 446: 1056-1061.

SCUDELLARI, M. (2009). Blood feuds. Nature online: Reports Stem Cells.

SHALABY, F., HO, J., STANFORD, W.L., FISCHER, K.D., SCHUH, A.C. SCHWARTZ, L., BERNSTEIN, A. and ROSSANT, J. (1997). A requirement for Flk1 in primitive and definitive hematopoiesis and vasculogenesis. Ce//89:981- 
990.

SORIANO, P. and JAENISCH, R. (1986). Retroviruses as probes for mammalian development: allocation of cells to the somatic and germ cell lineages. Cel/46: 19-29.

SUGIYAMA, D., OGAWA, M., HIROSE, I., JAFFREDO, T., ARAI, K. and TSUJI, K. (2003). Erythropoiesis from acetyl LDL incorporating endothelial cells at the preliver stage. Blood 101: 4733-4738.

TAKAKURA, N., HUANG, X.L., NARUSE, T., HAMAGUCHI, I., DUMONT, D.J., YANCOPOULOS, G.D. and SUDA, T. (1998). Critical role of the TIE2 endothelial cell receptor in the development of definitive hematopoiesis. Immunity 9 : 677-686.

TAM, P.P. and BEDDINGTON, R.S. (1987). The formation of mesodermal tissues in the mouse embryo during gastrulation and early organogenesis. Develop ment 99: 109-126.

TAM, P.P. and BEHRINGER, R.R. (1997). Mouse gastrulation: the formation of a mammalian body plan. Mech Dev 68: 3-25.

TAM, P.P. and TAN, S.S. (1992). The somitogenetic potential of cells in the primitive streak and the tail bud of the organogenesis-stage mouse embryo. Development 115: 703-715.

TAN, S.S. and BREEN, S. (1993). Radial mosaicism and tangential cell dispersion both contribute to mouse neocortical development. Nature 362: 638-640.

TARKOWSKI, A.K. (1961). Mouse chimaeras developed from fused eggs. Nature 190: 857-860.

TAVIAN, M., CORTES, F., CHARBORD, P., LABASTIE, M.C. and PEAULT, B. (1999). Emergence of the haematopoietic system in the human embryo and foetus. Haematologica 84 Suppl EHA-4: 1-3.

TOLES, J.F., CHUI, D.H., BELBECK, L.W., STARR, E. and BARKER, J.E. (1989). Hemopoietic stem cells in murine embryonic yolk sac and peripheral blood. Proc Natl Acad Sci U S A 86: 7456-7459.

UENO, H., TURNBULL, B.B. and WEISSMAN, I.L. (2009). Two-step oligoclonal development of male germ cells. Proc Natl Acad Sci US A 106: 175-180.

UENO, H. and WEISSMAN, I.L. (2006). Clonal analysis of mouse development reveals a polyclonal origin for yolk sac blood islands. Dev Ce//11: 519-533.
UENO, H. and WEISSMAN, I.L. (2007). Stem cells: blood lines from embryo to adult. Nature 446: 996-997.

VOGELI, K.M., JIN, S.W., MARTIN, G.R. and STAINIER, D.Y. (2006). A common progenitor for haematopoietic and endothelial lineages in the zebrafish gastrula. Nature 443: 337-339.

WAGERS, A.J. and WEISSMAN, I.L. (2004). Plasticity of adult stem cells. Ce//116: 639-648

WANG, Q., STACY, T., BINDER, M., MARIN-PADILLA, M., SHARPE, A.H. and SPECK, N.A. (1996). Disruption of the Cbfa2 gene causes necrosis and hemorrhaging in the central nervous system and blocks definitive hematopoiesis. Proc Nat/ Acad Sci US A 93: 3444-3449.

WANG, Y., YATES, F., NAVEIRAS, O., ERNST, P. and DALEY, G.Q. (2005) Embryonic stem cell-derived hematopoietic stem cells. Proc Nat/Acad Sci US A 102: 19081-19086.

WEISSMAN, I., PAPAIOANNOU, V. and GARDNER, R. (1978). Fetal Hematopoietic Origins of the Adult Hematolymphoid System. In Differentiation of Normal and Neoplastic Hematopoietic Cells. (Eds. B. Clarkson, PA Marks, JE Till). Cold Spring Harbor Laboratory Press, New York, pp. 33-47.

WEISSMAN, I.L., BAIRD, S., GARDNER, R.L., PAPAIOANNOU, V.E. and RASCHKE, W. (1977). Normal and neoplastic maturation of T-lineage lymphocytes. Cold Spring Harb Symp Quant Bio/41 Pt 1: 9-21.

WEISSMAN, I.L., WARNKE, R., BUTCHER, E.C., ROUSE, R. and LEVY, R. (1978). The lymphoid system. Its normal architecture and the potential for understanding the system through the study of lymphoproliferative diseases. Hum Pathol 9: $25-45$.

WEST, J.D. (1975). A theoretical approach to the relation between patch size and clone size in chimaeric tissue. J Theor Bio/50: 153-160.

WOOD, H.B., MAY, G., HEALY, L., ENVER, T. and MORRISS-KAY, G.M. (1997). CD34 expression patterns during early mouse development are related to modes of blood vessel formation and reveal additional sites of hematopoiesis. Blood 90: 2300-2311.

ZONG, H., ESPINOSA, J.S., SU, H.H., MUZUMDAR, M.D. and LUO, L. (2005). Mosaic analysis with double markers in mice. Cel/121: 479-492. 


\section{Further Related Reading, published previously in the Int. J. Dev. Biol.}

See our recent Special Issue Placenta edited by Joan S. Hunt and Kent L. Thornburg at: http://www.ijdb.ehu.es/web/contents.php?vol=54\&issue=2-3

Tracing the hemangioblast during embryogenesis: developmental relationships between endothelial and hematopoietic cells Thierry Jaffredo, Karine Bollerot, Daisuke Sugiyama, Rodolphe Gautier and Cécile Drevon Int. J. Dev. Biol. (2005) 49: 269-277

Of birds and mice: hematopoietic stem cell development Isabelle Godin and Ana Cumano Int. J. Dev. Biol. (2005) 49: 251-257

Embryonic development of the human hematopoietic system Manuela Tavian and Bruno Péault Int. J. Dev. Biol. (2005) 49: 243-250

Analysis of mouse eye development with chimeras and mosaics J. Martin Collinson, Robert E. Hill and John D. West Int. J. Dev. Biol. (2004) 48: 793-804

Multilineage hematopoietic progenitor activity generated autonomously in the mouse yolk sac: analysis using angiogenesisdefective embryos

Christine Rampon and Philippe Huber

Int. J. Dev. Biol. (2003) 47: 273-280

Embryonic stem cells and transgenic mice in the study of hematopoiesis S H Orkin

Int. J. Dev. Biol. (1998) 42: 927-934
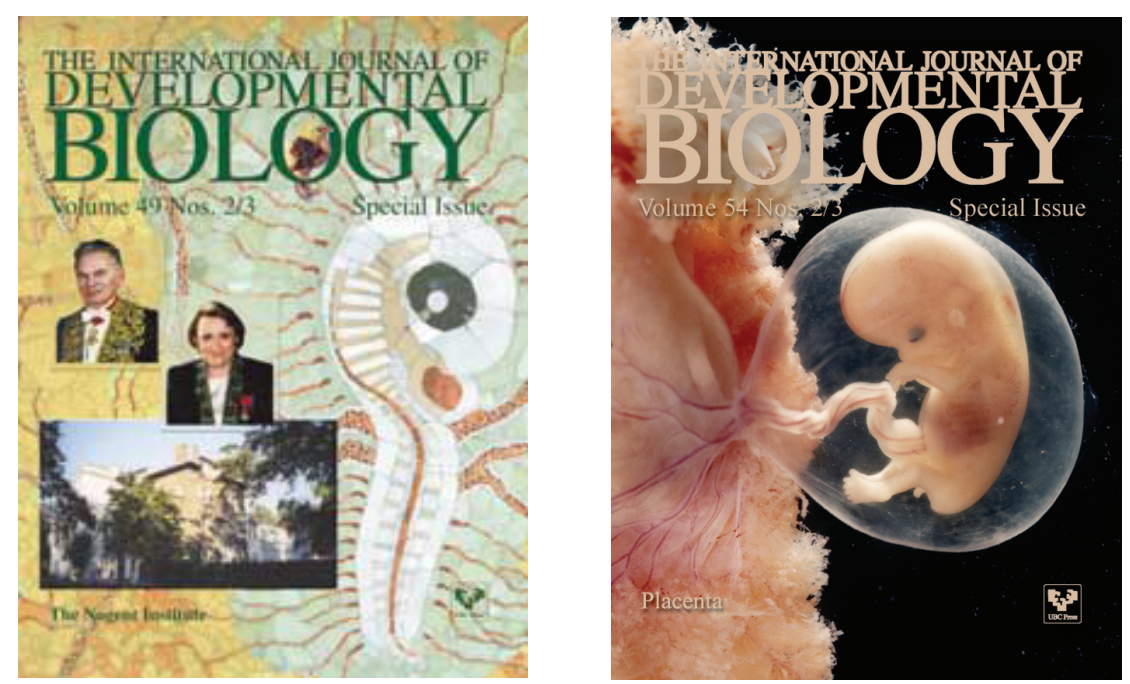

5 yr ISI Impact Factor $(2009)=3.253$

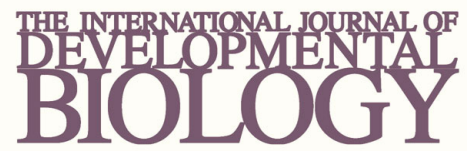

Volume 54 Nos. 6/7

Special Issue

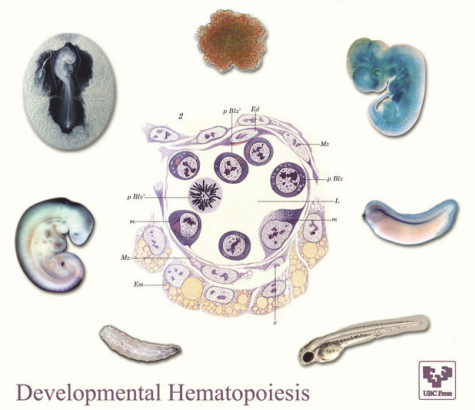

Developmental Hematopoiesis 